\title{
Morfologia foliar de Theobroma grandiflorum Schum
}

\author{
Foliar morphology of Theobroma grandiflorum Schum
}

\author{
Maria das Graças Rodrigues Ferreira' ${ }^{\mathrm{I}}$ Adriana Ema Nogueira ${ }^{\mathrm{II}}$ \\ Carlos Ferreira Damião Filho III
}

\begin{abstract}
As folhas de Theobroma grandiflorum Schum. são morfologicamente descritas. A espécie apresenta elementos histológicos comuns para a família, destacando-se tipos de tricomas, estômatos e contornos das células epidérmicas em visão frontal. Empregou-se microscopia eletrônica de varredura para a caracterização de segmentos foliares jovens, em que ficou evidenciada a presença de tricomas estrelados nas superfícies adaxial e abaxial dos mesmos. As folhas de cupuaçu são hipoestomáticas com número elevado de estômatos anomocíticos. As nervuras principais apresentaramse desprovidas de tricomas, com estômatos esparsamente distribuídos.
\end{abstract}

Palavras-chave: espécie nativa, tricomas, estômatos.

\section{ABSTRACT}

The cupuassu leaves are morphologically described. The species present common histological elements in the family, showing types of trichomes, stomata and epidermal cells on the surface view. Young foliar segments were photographed with scanning electron microscopy, where trichomes with star form were detected in the adaxial and abaxial epidermis. The cupuassu leaves are hypostomatic with high numbers anomocytic stomata. The main veins of the cupuassu leaves did not show trichomes, and stomata were sparsely distributed.

Key words: native specie, trichomes, stomata.

O cupuaçuzeiro (Theobroma grandiflorum) é uma árvore frutífera, pertencente à família das
Sterculiaceas, tipicamente amazônica, que encontrase em estado silvestre na parte sul e sudeste da Amazônia Oriental e noroeste do Estado do Maranhão. A espécie encontra-se atualmente disseminada por toda a bacia amazônica, sendo esporadicamente encontrada em outros países como a Colômbia, Venezuela, Equador e Costa Rica (VENTURIERI et al., 1985).

As folhas apresentam ápice acuminado, borda lisa e base obtusa (MODESTO \& SIQUEIRA, 1981). O conhecimento da anatomia foliar de Theobroma grandiflorum, com relação às características da epiderme (presença de cutícula, localização de estômatos e tricomas), pode promover diferença na absorção de nutrientes pelas faces adaxial e abaxial, tornando a prática da adubação foliar mais eficiente (LEECE, 1976; KANNAN, 1980). Pode auxiliar, também, no estudo histopatológico, por meio da avaliação comparativa das alterações das estruturas internas da planta sadia e doente, permitindo diferenciar, até certo ponto, a resistência do material botânico. Assim, o objetivo deste trabalho foi apresentar a descrição morfológica das folhas de cupuaçu, enfatizando aspectos da epiderme para obtenção de informações que possam fornecer subsídios para correlações com dados fisiológicos, bem como auxiliar estudos histopatológicos.

Para o estudo da morfologia da superfície foliar do cupuaçu, folhas foram coletadas da coleção

IEmbrapa Rondônia, BR 364, Km 5,5, CP 406, 78900-970, Porto Velho, RO, Brasil. E-mail: mgraca@cpafro.embrapa.br. *Autor para correspondência.

"Faculdade São Lucas, Porto Velho, RO, Brasil.

IIIDepartamento de Biologia Aplicada à Agropecuária, Faculdade de Ciências Agrárias e Veterinárias (FCAV), Universidade Estadual Paulista (UNESP). 
de plantas, localizada na Fazenda Experimental da Faculdade de Ciências Agrárias e Veterinárias, campus de Jaboticabal, UNESP. As folhas foram conduzidas ao Laboratório de Microscopia Eletrônica de Varredura, onde foram segmentadas em pedaços com aproximadamente $0,5 \mathrm{~cm}^{2}$ de área. A seguir, foram fixadas, a $4^{\circ} \mathrm{C}$, em glutaraldeído a $3 \%$, em tampão de fosfato de potássio a $0,1 \mathrm{M}$ e $\mathrm{pH} 7,4$ por 72 horas. A seguir, as folhas foram lavadas na solução tampão pura por cinco vezes consecutivas, em um intervalo de 15 minutos, e pós-fixadas em tetróxido de ósmio a $2 \%$ no mesmo tampão a $4^{\circ} \mathrm{C}$, por cerca de 12 horas. $\mathrm{Na}$ seqüência, foram novamente lavadas como no caso anterior, desidratadas em série gradual de etanol, secas em secador de ponto crítico utilizando-se $\mathrm{CO}_{2}$, montadas, metalizadas com 35nm de ouro-paládio, observadas e elétron-micrografadas em microscópio eletrônico de varredura JEOL JSM 5410, operado em $15 \mathrm{KV}$.

Na epiderme da face adaxial da folha (Figura 1A), ocorrem tricomas compostos, e estrelados, esparsamente distribuídos pela superfície. Verifica-se a ausência de estômatos. Além disso, as paredes anticlinais e periclinais externas das células epidérmicas fundamentais não são evidentes, sendo que a superfície foliar superior assemelha-se a um plano homogêneo, sem definição dos contornos superficiais das suas unidades celulares fundamentais.

Observando-se a figura $1 \mathrm{~B}$, a qual documenta um corte transversal da folha de cupuaçu ao MEV, verifica-se que a aparência frontal da epiderme superior da folha, descrita como a de um plano homogêneo, é devida às características celulares das células epidérmicas fundamentais da superfície adaxial. Estas são pequenas, com formato tipicamente tabular, de paredes espessas, sem espaços intercelulares, com as paredes periclinais externas dispostas em mesmo nível, sendo recobertas por uma espessa cutícula, o que dificulta a visualização dos contornos celulares em vista frontal. Também evidenciam-se, imediatamente abaixo da epiderme da face adaxial, duas camadas de tecido parenquimático em paliçada, apresentando células mais altas que largas e poucos espaços intercelulares. Em continuidade a estas, seguindo-se em direção à epiderme da face abaxial, encontram-se duas camadas de tecido de parênquima densamente arranjadas, com poucas lacunas evidentes, apresentando formato irregular com projeções laterais, conectadas às células adjacentes, delimitando espaços intercelulares, que podem ter amplitudes variadas. A camada de células epidérmicas fundamentais da superfície abaxial, ao contrário do observado para as da superfície superior, são compostas por células de paredes periclinais externas abauladas, aparentando serem desprovidas de cutícula (ou esta ser muito tênue), sendo dispostas em diferentes níveis, fato este que pode evidenciar os seus contornos, em observação frontal.

Os tricomas presentes na superfície adaxial da folha (Figura 1C) são pêlos compostos, estrelados, formados por oito ramificações, actinomorfos, com simetria multilateral, rotados (distribuídos em um único plano), sendo cada ramificação formada por uma única célula. No centro do tricoma, verifica-se uma base circular, da qual emergem todos as ramificações do pêlo. A análise da figura 1D, que mostra a superfície abaxial da folha de cupuaçu, em vista frontal, observada ao $\mathrm{MEV}$, evidencia a presença de dois tipos de tricomas compostos, ambos estrelados, com dois diferentes tamanhos, sendo os menores com distribuição mais densa do que a da superfície superior e em maior número do que os tricomas maiores. De acordo com EHLERINGER (1984), o valor adaptativo dos tricomas foliares está relacionado à economia de água pelo vegetal, através de um aumento na reflexão da radiação solar, que reduz a temperatura foliar e conseqüentemente a transpiração, ou através do aumento da espessura da camada de ar pela qual a água deve difundir-se. Na superfície inferior, ao contrário do observado na superior, as células epidérmicas fundamentais são conspícuas, mesmo sendo a observação frontal das mesmas prejudicada pela densa cobertura dos tricomas e pelo elevado número de estômatos.

Os estômatos, observados com maior aproximação na figura 1E, são densamente distribuídos e volumosos, encontrados em um nível inferior aos dos tricomas estrelados. Os estômatos são do tipo anomocítico e volumoso em relação à superfície na qual estão dispostas as células epidérmicas fundamentais e estão presentes na face inferior ou abaxial da folha, classificada como hipoestomática (METCALF \& CHALCK, 1957), o que confere ao cupuaçuzeiro condições de adaptação para suportar altas incidências de luz (FAHN, 1985). Vemos, em detalhe, que as duas células-guarda, projetando-se sobre a superfície da folha, formam uma estrutura colunar, estreita na base e expandida na extremidade, no cimo da qual observa-se o poro estomático. Os ostíolos, conforme vistos nas figuras $1 \mathrm{E}$ e $1 \mathrm{~F}$, na sua maioria, encontravam-se abertos por ocasião das fotomicrografias, indicando ser lento o mecanismo de abertura e fechamento dos mesmos.

O cupuaçuzeiro apresenta pecíolo curto e nervuras principal e secundárias proeminentes na face abaxial (Figura 2 A e B), desprovidas de tricomas, possuindo estômatos esparsamente distribuídos. Tais 

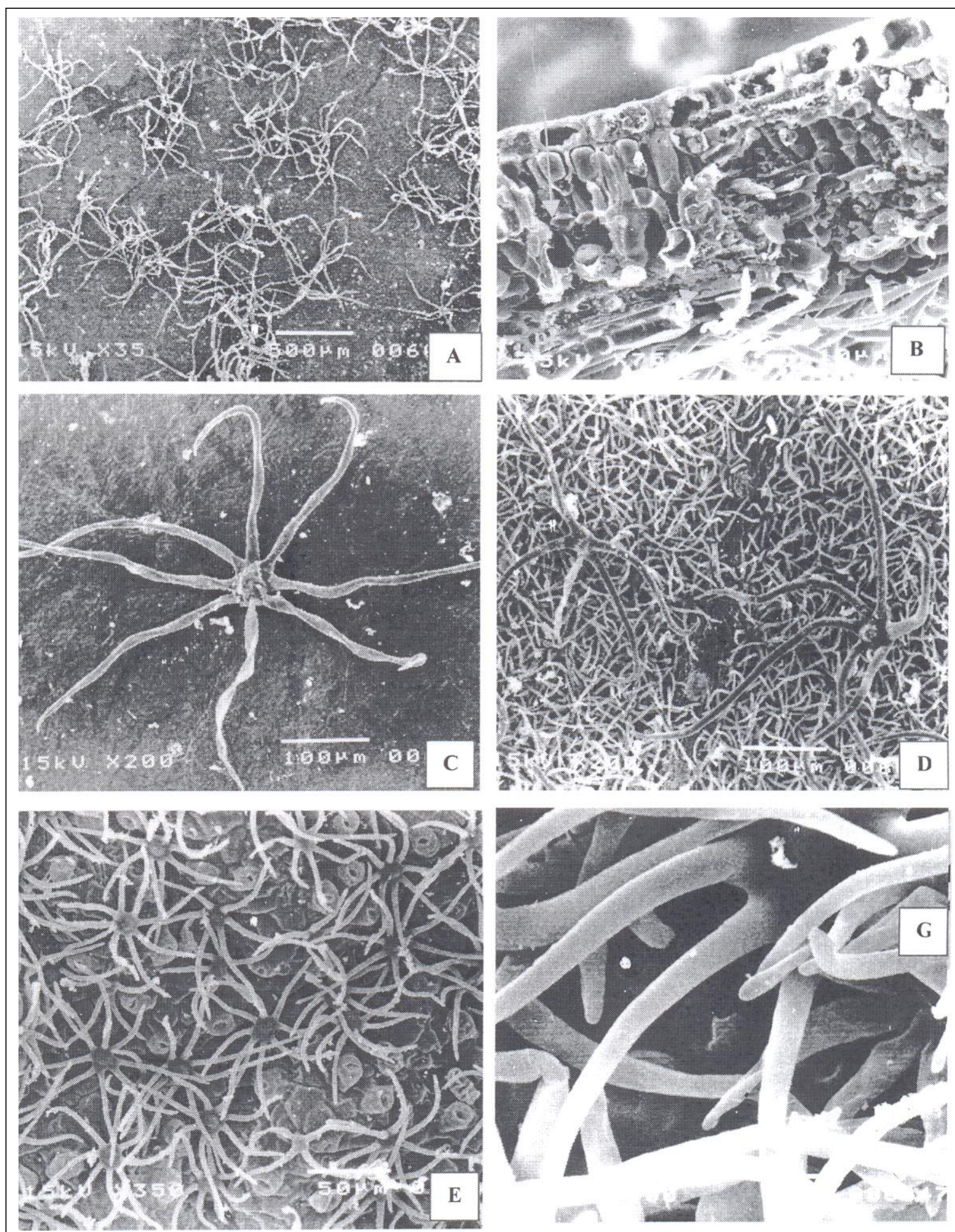

Figura 1 - Micrografias (MEV) de folhas de cupuaçu. A. Superfície adaxial evidenciando tricomas; B. Corte transversal de folha. pp - parênquima paliçádico; pl - parênquima lacunoso; $\mathrm{t}$ - tricomas; C. Detalhe de tricoma da superfície adaxial; D. Superfície abaxial da folha; com dois tipos de tricomas. Seta indica tricoma de maior tamanho; E. Detalhe da superfície abaxial. Seta indica o estômato; F. G. Detalhe dos estômatos cobertos por tricomas. 

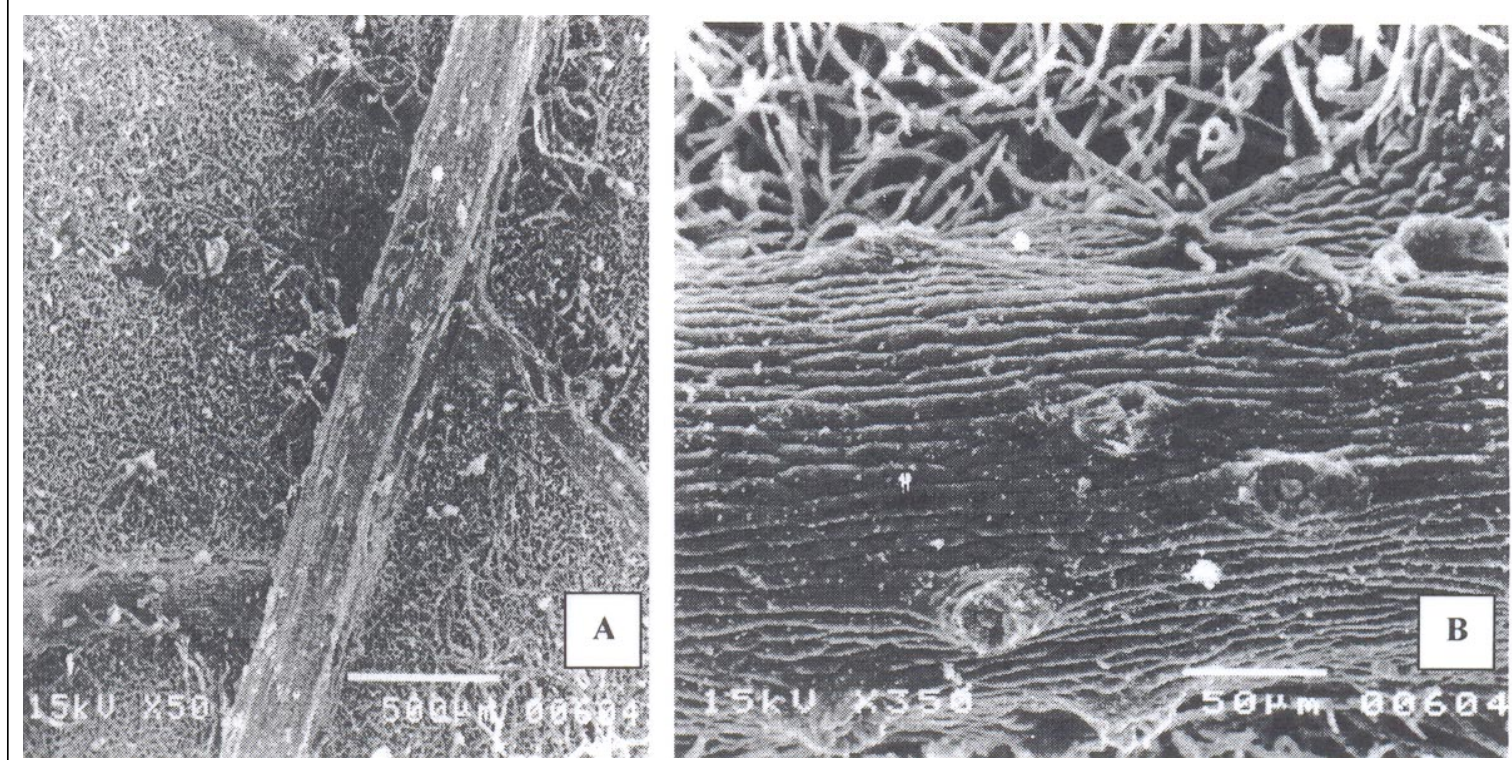

Figura 2 - Superfície abaxial de folha de cupuaçu. A. Visão geral da folha mostrando nervura principal e ramificações; B. Detalhe da nervura principal mostrando estômatos.

estômatos são morfologicamente diferentes dos das demais regiões da folha, apresentando-se com menor altura do que os do tipo "colunar", anteriormente descritos, e com o poro estomático de maior diâmetro do que os dos anteriores, o que também foi constatado por GOMES \& KOZLOWSKI (1988) e HARDWICK et al. (1983) para o cacau.

No presente trabalho constatou-se que as folhas de cupuaçu apresentam um ápice acuminado, a borda lisa e a base obtusa. Oservou-se também que ocorrem tricomas estrelados nas superfícies adaxial e abaxial de folhas de cupuaçu; as folhas de cupuaçu. Além disso, constatou-se que são hipoestomáticas com número elevado de estômatos anomocíticos. Por fim, as nervuras principal e secundárias proeminentes na face abaxial de folhas de cupuaçu apresentaram-se desprovidas de tricomas, com estômatos esparsamente distribuídos.

\section{REFERÊNCIAS}

EHLERINGER, J. Ecology and ecophysiology of leaf pubescence in North American desert plants. In: RODRIGUEZ, E. et al. Biology and chemistry of plant trichomes. New York: Plenum, 1984. p.113-133.
FAHN, A. Anatomía vegetal. Madrid: Pirámide, 1985. 599p.

GOMES, A.R.S.; KOZLOWSKI, T.T. Stomatal characteristics, leaf waxes and transpiration rates of Theobroma cacao and Hevea brasiliensis seedlings. Annals of Botany, London, v.61, n.4, p.425-432, 1988.

HARDWICK, K. et al. Surface characteristics of cacao leaves. Cacao Café Thé, Paris, v.27, n.4, p.241-244, 1983.

KANNAN, S. Mechanisms of foliar uptake of plant nutrients: accomplishments and prospects. Journal of Plant Nutrition, New York, v.2, p.717-735, 1980.

LEECE, D.R. Composition and ultrastructure of leaf cuticles from fruit trees, relative to differential foliar absorption. Australian Journal of Plant Physiology, Melbourne, v.3, n.6, p.833-847, 1976.

METCALF, C.R.; CHALCK, L. Anatomy of the dicotyledons. Oxford: Clarendon, 1957. 724p.

MODESTO, Z.M.M.; SIQUEIRA, N.J.B. Botânica. São Paulo: EPU, 1981. 36p.

VENTURIERI, G.A. et al. O cultivo do cupuaçuzeiro. Informativo SBF, Campinas, v.4, n.1, p.15-17, 1985. 